\title{
Acute 5-HT7 receptor activation increases NMDA- evoked currents and differentially alters NMDA receptor subunit phosphorylation and trafficking in hippocampal neurons
}

\author{
Maryam S Vasefi', Kai Yang ${ }^{2}$, Jerry Li', Jeff S Kruk', John J Heikkila', Michael F Jackson, John F MacDonald ${ }^{3}$ \\ and Michael A Beazely ${ }^{4^{*}}$
}

\begin{abstract}
Background: N-methyl-D-aspartate (NMDA) receptors are regulated by several G protein-coupled receptors (GPCRs) as well as receptor tyrosine kinases. Serotonin (5-HT) type 7 receptors are expressed throughout the brain including the thalamus and hippocampus. Long-term (2-24 h) activation of 5-HT7 receptors promotes the expression of neuroprotective growth factor receptors, including the platelet-derived growth factor (PDGF) $\beta$ receptors which can protect neurons against NMDA-induced neurotoxicity.

Results: In contrast to long-term activation of 5-HT7 receptors, acute (5 min) treatment of isolated hippocampal neurons with the 5-HT7 receptor agonist 5-carboxamidotryptamine (5-CT) enhances NMDA-evoked peak currents and this increase in peak currents is blocked by the 5-HT7 receptor antagonist, SB 269970. In hippocampal slices, acute 5-HT7 receptor activation increases NR1 NMDA receptor subunit phosphorylation and differentially alters the phosphorylation state of the NR2B and NR2A subunits. NMDA receptor subunit cell surface expression is also differentially altered by $5-\mathrm{HT} 7$ receptor agonists: NR2B cell surface expression is decreased whereas NR1 and NR2A surface expression are not significantly altered.

Conclusions: In contrast to the negative regulatory effects of long-term activation of 5-HT7 receptors on NMDA receptor signaling, acute activation of 5-HT7 receptors promotes NMDA receptor activity. These findings highlight the potential for temporally differential regulation of NMDA receptors by the 5-HT7 receptor.
\end{abstract}

Keywords: 5-HT7, NMDA, Hippocampus, Isolated neurons, Phosphorylation, Trafficking

\section{Background}

$\mathrm{N}$-methyl-D-aspartate (NMDA) receptors are tetrameric channels composed of two NR1 and two NR2 or NR3 subunits [1]. In the hippocampus, most NR2 subunits are either NR2A or NR2B [2] and there is evidence that heterotrimeric NMDA receptors containing both NR2A and NR2B are also present [3]. Several studies have examined the ability of serotonin (5-HT) receptors to modulate NMDA receptor activity. For example, in isolated cortical neurons, activation of 5-HT1A receptors inhibits NMDA receptor currents [4] and 5-HT3 receptor activation

\footnotetext{
* Correspondence: mbeazely@uwaterloo.ca

${ }^{4}$ School of Pharmacy, 200 University Ave. W, Waterloo, ON N2L 3G1, Canada Full list of author information is available at the end of the article
}

reduces NMDA receptor currents in cortical slices [5]. In contrast, in Xenopus oocytes, 5-HT2 receptor activation increases NMDA receptor currents [6] and in prefrontal cortical slices, 5-HT2A/2C agonists enhance NMDA-evoked responses [7].

Although first identified in the suprachiasmatic nucleus, 5-HT7 receptors are expressed throughout the CNS, including the hippocampus [8]. The effect of 5-HT7 receptor ligands on NMDA-evoked currents remains unknown however recent studies provide clear evidence for the regulation of glutamatergic signaling by 5 -HT7 receptors. 5-HT7 receptors inhibit NMDA-induced neurotransmitter release in the dorsal raphe nucleus (DRN) and the physiological role of 5-HT7 receptors in circadian rhythms is 




B
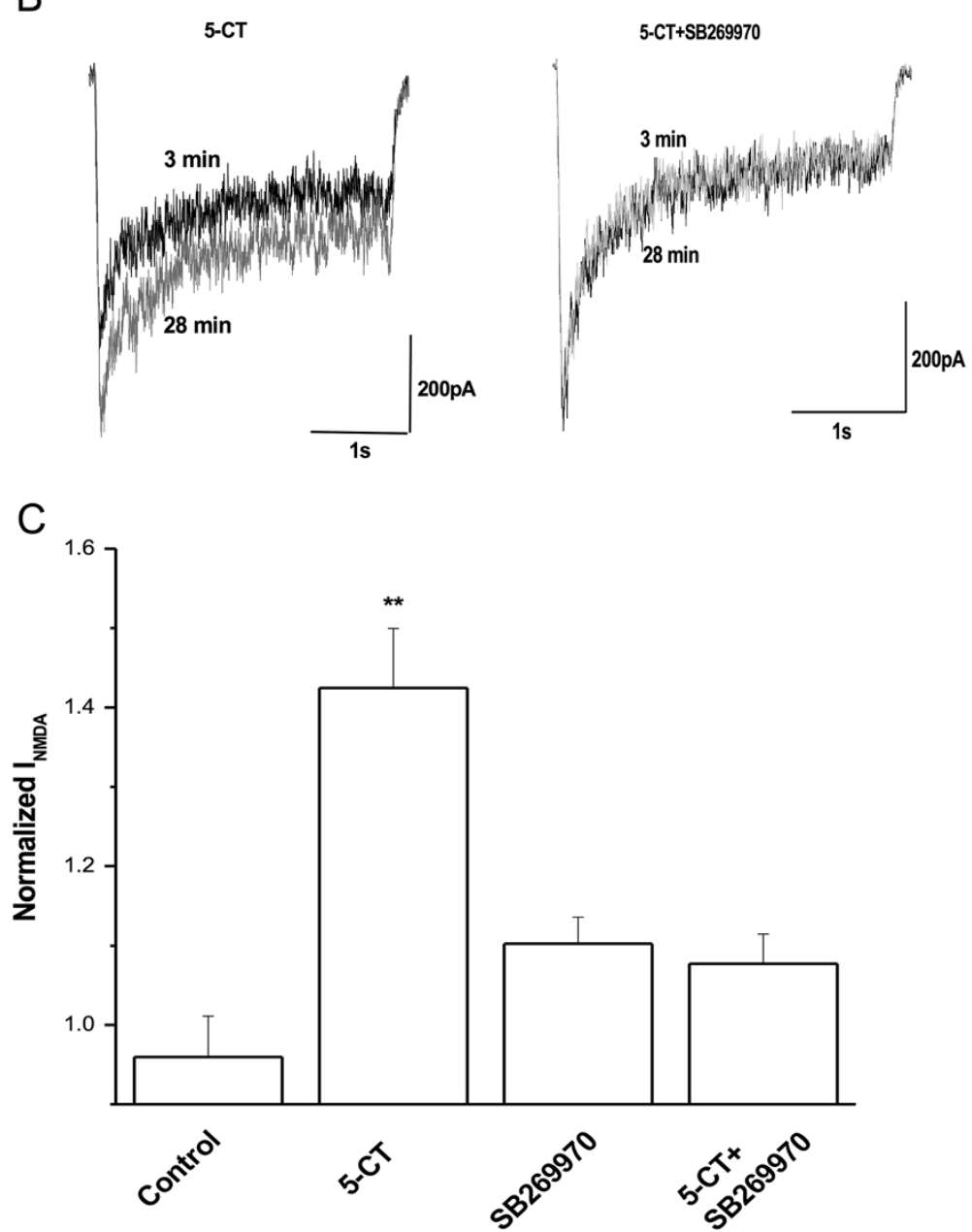

Figure 1 (See legend on next page.) 
(See figure on previous page.)

Figure 1 5-HT7 receptor activation increases NMDA-evoked currents in isolated hippocampal neurons. A) $50 \mathrm{nM}$ 5-CT was applied to isolated CA1 hippocampal neurons for 5 min beginning at min 5 after a stable baseline of NMDA-evoked currents was established (closed circles). For the control data, vehicle (ECF) was continuously applied for $30 \mathrm{~min}$. In samples treated with the 5-HT7 receptor antagonist, SB 269970 $(1 \mu \mathrm{M})$ was included in the bath and was present before, during, and after 5-CT application. NMDA-evoked currents were recorded every $60 \mathrm{~s}$ by application of $50 \mu \mathrm{M}$ NMDA, $0.5 \mu \mathrm{M}$ glycine for $3 \mathrm{~s}$. Recordings continued for at least 20 min after drug application. Peak currents were averaged for 5 min prior to applying 5-CT and were compared with currents averaged for values between 26 and 30 min. Data are representative of 5-6 independent experiments for each condition. B) Sample traces from the same cell treated with $50 \mathrm{nM}$ 5-CT are shown at minute 3 (black trace) or minute 28 (gray trace). C) 5-HT7 antagonist SB269970 prevents the enhancement of $I_{\text {NMDA }}$ by 5-CT. ** Indicates $p<0.01$, one-way ANOVA (Turkey's post hoc comparison).

associated with an inhibition of glutamate-dependent events $[9,10]$. In the suprachiasmatic nucleus, glutamate excitatory post-synaptic potentials (EPSPs) and glutamateinduced intracellular calcium levels are both inhibited by 5 -HT7 receptor activation $[11,12]$. Taken together, these studies suggest that 5-HT7 receptor activation decreases NMDA and/or glutamate receptor signaling. In contrast, compared to wild-type, 5-HT7 receptor knock-out mice display a reduced induction of long-term potentiation (LTP), magnitude of LTP, and hippocampusassociated learning [13]. Therefore, although there is evidence that 5-HT7 receptors negatively regulate NMDA/ glutamate signaling, deletion of 5-HT7 receptors decreased the magnitude of NMDA receptor-dependent events such as LTP.

5-HT7 receptors are $G \alpha_{s}-$ coupled, although they may couple to additional $\mathrm{G} \alpha$ isoforms including $\mathrm{G \alpha}_{12}$ [14,15]. Recently we identified the 5-HT7 receptor as a regulator of platelet-derived growth factor (PDGF) $\beta$ receptor expression and activity [16]. Activation of PDGF $\beta$ receptors by PDGF-BB selectively inhibits NR2B-containing NMDA receptor currents and this may be involved in the mechanism of PDGF $\beta$ receptor-mediated neuroprotection [17]. Intriguingly, 5-HT7 receptor-induced upregulation of the PDGF $\beta$ receptor was sufficient to protect neurons against NMDA-induced excitotoxicity [18]. Thus, we proposed that long-term activation of 5-HT7 receptors initiates pathways that ultimately negatively regulate NMDA receptor signaling.

To clarify the direct effects of 5-HT7 receptor activation on NMDA receptor signaling we examined the effects of 5-HT7 receptor agonists and antagonists on NMDA-evoked currents, NMDA receptor subunit phosphorylation, and subunit cell surface expression in the hippocampus. In isolated hippocampal neurons, application of the 5-HT7 receptor agonist, 5-CT, resulted in a rapid and sustained increase in peak NMDA-evoked currents. 5-HT7 receptor agonist treatment also differentially altered NMDA receptor subunit phosphorylation and cell surface expression. These data, along with our previous work, suggest a model for differential NMDA receptor regulation by 5 -HT7 receptors over the shortand long-term.

\section{Results}

Application of the 5-HT7 receptor agonist, 5-CT, to isolated hippocampal neurons for $5 \mathrm{~min}$ increased NMDAevoked peak currents (Figure 1). NMDA receptor currents were evoked once every $1 \mathrm{~min}$ using a $3 \mathrm{~s}$ exposure to NMDA $(50 \mu \mathrm{M})$ and glycine $(0.5 \mu \mathrm{M})$. 5-CT was applied in the bath continuously for $5 \mathrm{~min}$ after a 5 -min stable baseline recording. This application increased NMDAevoked currents to $142.5 \pm 7.4 \%(n=5)$ compared with baseline, whereas NMDA-evoked currents in control cells were stable over the recording period $(95.9 \pm 5.2 \%$, $\mathrm{n}=6)(\mathrm{p}<0.01$, one way ANOVA (Tukey's post hoc comparison), Figure 1). The 5-CT-induced increase in NMDA-evoked currents was observed within minutes after 5-CT application and the increase in peak currents was sustained even after $5-\mathrm{CT}$ was washed out (min 10 through 30). In addition to 5-HT7, 5-CT also activates 5-HT1 and 5-HT5 receptors [19,20]. However, the increase in NMDA-evoked currents by 5-CT was completely blocked by the 5-HT7 receptor-selective antagonist, SB 269970 (Figure 1).

To determine if 5-HT7 receptor activation altered NMDA receptor subunit phosphorylation we incubated hippocampal slices with $50 \mathrm{nM} 5$-CT in the absence or presence of SB 269970. 5-HT7 receptors are coupled to Gos in several cell lines [14,21-25] and the application of 5-CT to hippocampal slices robustly increased NR1 receptor phosphorylation at the PKA phosphorylation site, serine 897 (Table 1). 5-CT application also increased the phosphorylation of the NR1 subunit at PKC-site serine 896 (Table 1). The increase in the PKC-site serine 896 phosphorylation was blocked by the PKC inhibitor Go 6983 (Figure 2A) and the increase in the PKA-site serine 897 phosphorylation was blocked by the PKA inhibitor, H89 (Figure 2B). In Figure 1, a 5 min application of 5-CT resulted in a sustained elevation of NMDAevoked currents for at least $20 \mathrm{~min}$ after washout. To determine if the observed changes in NR1 subunit phosphorylation were similarly sustained we treated hippocampal slices with 5-CT for $5 \mathrm{~min}$, washed the slices, and waited an additional $20 \mathrm{~min}$ before homogenizing the tissue in lysis buffer. The phosphorylation state of both serines 896 and 897 remained significantly 
Table 1 5-CT treatment differentially alters NMDA receptor subunit phosphorylation

\begin{tabular}{lccc}
\hline $\begin{array}{l}\text { NMDAR subunit/ } \\
\text { phosphorylation site }\end{array}$ & \multicolumn{3}{c}{ Treatment (5 min) } \\
\cline { 2 - 4 } & $\mathbf{5 - C T}$ & $\mathbf{5 - C T}+$ SB & SB 269970 \\
\hline NR1/896, $n=8$ & $2.07 \pm 0.39^{* *}$ & $0.91 \pm 0.31$ & $1.06 \pm 0.28$ \\
NR1/897, $n=8$ & $1.51 \pm 0.13^{* *}$ & $1.00 \pm 0.39$ & $0.95 \pm 0.11$ \\
NR2A/total, $n=10$ & $0.71 \pm 0.07^{* *}$ & $0.97 \pm 0.37$ & $0.86 \pm 0.17$ \\
NR2B/1472, $n=5$ & $2.79 \pm 0.37^{* *}$ & $1.49 \pm 0.61$ & $2.86 \pm 1.33$ \\
NR2B/1252, $n=10$ & $1.39 \pm 0.49$ & $1.50 \pm 0.23$ & $1.53 \pm 0.31$ \\
NR2B/1336, $n=7$ & $1.25 \pm 0.19$ & $1.98 \pm 0.31$ & $2.36 \pm 0.36^{* *}$ \\
\hline
\end{tabular}

Hippocampal slices were treated with $50 \mathrm{nM} 5-\mathrm{CT}$ in the absence or presence of 1 MM SB 269970 for $5 \mathrm{~min}$. Changes in the phosphorylation state for each antibody were normalized to control (vehicle-treated slices) and to total NR subunit expression. For each experiment a $\beta$-actin antibody was used to confirm equal loading. Data presented are the average and standard error. ${ }^{*} p<0.5,{ }^{* *} p<0.01$, compared to vehicle. elevated above control for $20 \mathrm{~min}$ after the treatment with 5-CT (Figure 2C, D).

As mentioned above, 5-CT will also activate 5-HT1 and 5-HT5 receptors $[19,20]$. To confirm that the observed changes in NMDA receptor subunit phosphorylation were indeed due to the activation of the 5-HT7 receptor we incubated acutely-dissected hippocampal slices with the 5-HT7 receptor-selective agonist, LP 12 [26], in the absence or presence of the 5-HT7 receptor antagonists, SB 269970 and SB 258719 [27]. Similar to 5-CT, LP 12 increased NR1 receptor phosphorylation at the PKA phosphorylation site, serine 897 (Figure 3A, C) and this increased phosphorylation was sustained for at least $20 \mathrm{~min}$ (Figure 2D). Interestingly, we observed a larger increase in the phosphorylation of the adjacent, PKC-phosphorylated serine 896 (Figure 3B, C). However, the magnitude of the increase in serine 896 compared to

\section{A}

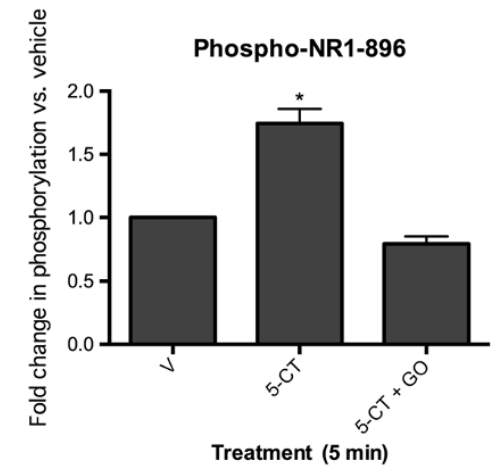

C

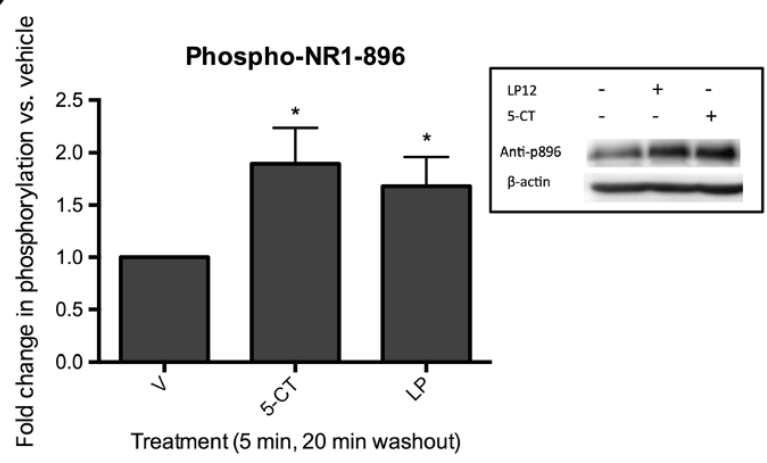

B

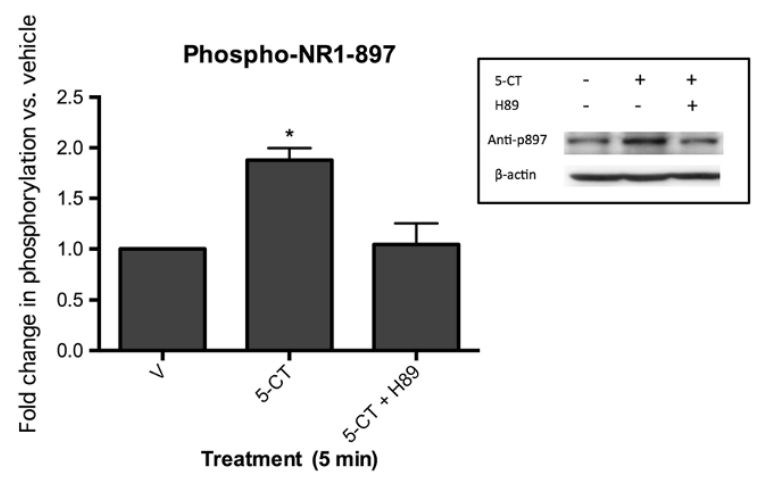

D

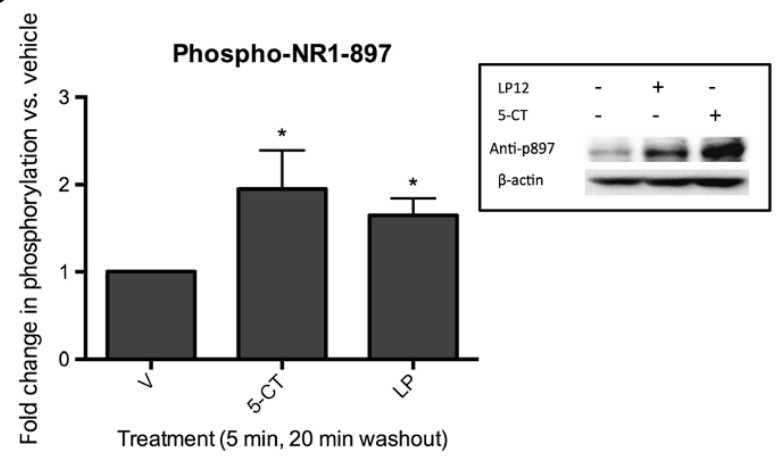

Figure 2 5-CT treatment of hippocampal slices increases NR1 phosphorylation at serines $\mathbf{8 9 6}$ and $\mathbf{8 9 7}$. A) Hippocampal slices were treated with 50 nM 5-CT in the absence or presence of 1 (micro)M Go 6983 (GO) for 5 min. Increases in the phosphorylation state at serine 896 were normalized to control (vehicle-treated slices) and to total NR1. Data represent the average and standard error of 10 independent experiments. ${ }^{*} p<0.5$ compared to vehicle, ANOVA analysis with Dunnett's post-test. INSET: representative Western blots showing serine 896 phosphoryaltion and the $\beta$-actin loading control. B) Hippocampal slices were treated with 50 nM 5 -CT in the absence or presence of $10 \mu \mathrm{M}$ H89 for 5 min. Data represent the average and standard error of 10 independent experiments. * $p<0.5$ compared to vehicle, ANOVA analysis with Dunnett's post-test. INSET: representative Western blots showing serine 897 phosphoryaltion and the $\beta$-actin loading control. C) Hippocampal slices were treated with $50 \mathrm{nM} 5-\mathrm{CT}$ or $300 \mathrm{nM}$ LP 12 for 5 min, the slices were washed and incubated in drug-free buffer for an additional 20 min before lysis. Data represent the average and standard error of 8 independent experiments. * $p<0.5$ compared to vehicle, ANOVA analysis with Dunnett's post-test. INSET: representative Western blots showing serine 896 phosphoryaltion and the $\beta$-actin loading control. D) Slices were treated as in C. Data represent the average and standard error of 4 independent experiments. * $p<0.5$ compared to vehicle, ANOVA analysis with Dunnett's post-test. INSET: representative Western blots showing serine 897 phosphoryaltion and the $\beta$-actin loading control. 

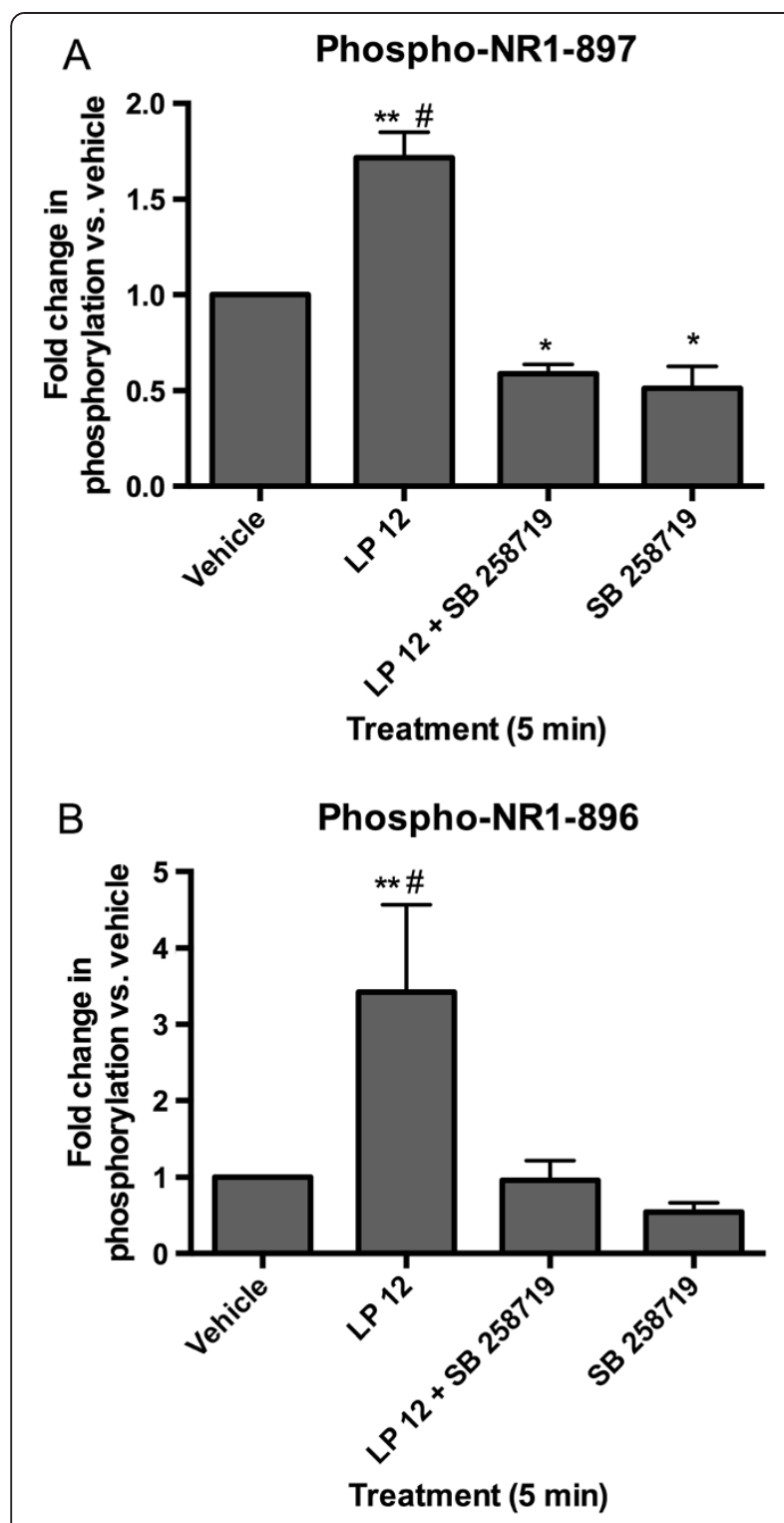

C

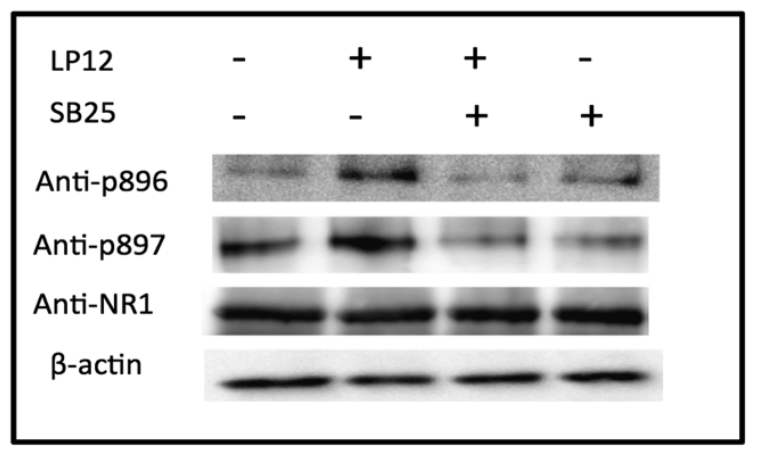

Figure 3 5-HT7 receptor activation increases NR1 subunit phosphorylation. A) Hippocampal slices were treated with $300 \mathrm{nM}$ LP 12 in the absence or presence of $1 \mu M$ SB 258719 for 5 min. Increases in the phosphorylation state at serine 897 were normalized to control (vehicle-treated slices) and to total NR1. Data represent the average and standard error of 9 independent experiments. ${ }^{* *} p<0.01$ LP 12 vs. vehicle, $\# p<0.01$ vs. LP 12 vs. LP $12+S B 258719$, * $p<0.5$ compared to vehicle, ANOVA analysis with Bonferroni's post-test. B) Hippocampal slices were treated as in A and western blots were performed using an anti-phospho-serine 896 antibody. Data represent the average and standard error of 10 independent experiments. ** $p<0.01$ LP 12 vs. vehicle, \# $p<0.01$ vs. LP 12 vs. LP $12+$ SB 258719, ANOVA analysis with Bonferroni's post-test. C) Representative Western blots showing serine 896 and serine 897 phosphorylation, total NR1, and $\beta$-actin.

serine 897 may be due to the lower basal phosphorylation state at serine 896. The increase in serine 896 phosphorylation was also observed for at least $20 \mathrm{mi}-$ nutes after LP 12 treatment (Figure 2C). The increased phosphorylation by LP 12 at both sites was blocked by the 5-HT7 receptor antagonists, SB 258719 (Figure 3) and SB 269970 (data not shown).

Application of LP 12 also differentially affected NR2 subunit phosphorylation. While LP 12 significantly reduced the phosphorylation state of the NR2A subunit (Figure 4A, B), LP 12 increased NR2B phosphorylation at tyrosine 1472 (Figure 4C, D). However the phosphorylation of NR2B at other tyrosine residues, 1252 and 1336, remained unchanged, with LP 12 inducing a $0.97 \pm$ $0.12(\mathrm{n}=12)$ and $0.93 \pm 0.11(\mathrm{n}=10)$ fold change, respectively, compared to control. The effects of LP 12 on the phosphorylation of NR2A and NR2B-Y1472 were both blocked by SB 258719 (Figure 4) and SB 269970 (data not shown). 5-CT treatment similarly enhanced NR2B-Y1472 phosphorylation and decreased NR2A phosphorylation (Table 1).

Several receptors and signaling pathways regulate NMDA receptor subunit cell surface expression. To investigate the effects of 5-HT7 receptor agonist treatment on the cell surface expression of the NMDA receptors subunits we treated hippocampal slices with LP 12 in the absence or presence of SB 258719 for $5 \mathrm{~min}$. In hippocampal slices LP 12 treatment did not significantly change the cell surface expression of NR1 $(0.92 \pm 0.13$ vs. control) and NR2A (1.05 \pm 0.13 vs. control), but NR2B cell surface expression was reduced by approximately $25 \%$ and this effect was blocked by SB 258719 (Figure 5).

\section{Discussion}

5-HT7 receptor knock-out mice display a reduced induction of LTP [13] and our finding that the acute 5-HT7 receptor activation increases NMDA-evoked currents may contribute to our understanding of how 5-HT7 receptors 

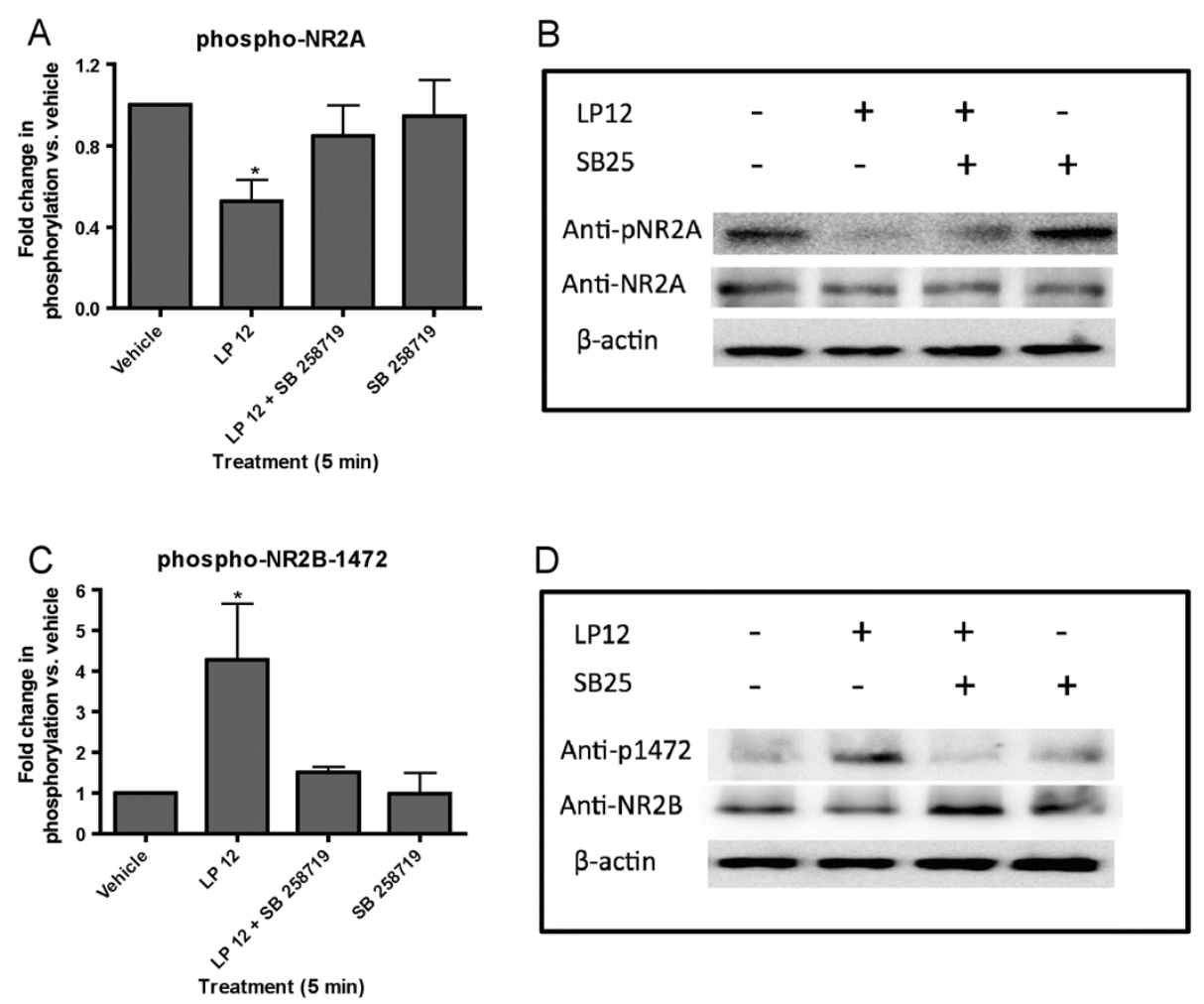

Figure 4 5-HT7 receptor activation differentially alters NR2 subunit phosphorylation. A) Hippocampal slices were treated with 300 nM LP 12 in the absence or presence of $1 \mu \mathrm{M}$ SB 258719 for 5 min. Decreases in the phosphorylation state of NR2A were normalized to control (vehicletreated slices) and to total NR2A. Data represent the average and standard error of 7 independent experiments. ${ }^{*} \mathrm{p}<0.05$ LP 12 vs. vehicle ANOVA analysis with Dunnett's post-test. B) Representative Western blots using anti-phospho-pan-NR2A, NR2A, and $\beta$-actin. C) Hippocampal slices were treated as in A. Increases in the phosphorylation state of NR2B at tyrosine 1472 were normalized to control (vehicle-treated slices) and to total NR2B. Data represent the average and standard error of 6 independent experiments. ${ }^{*} p<0.05$ LP 12 vs. vehicle ANOVA analysis with Dunnett's post-test. D) Representative Western blots using anti-phospho-Y1472-NR2B, NR2B, and $\beta$-actin.

modulate synaptic plasticity. 5-HT7 receptor-mediated increases in NMDA-evoked currents may also contribute of our understanding of how 5-HT7 receptor activation potentiates bursting frequency in the CA3 hippocampal neurons [28] and increases CA1 extracellular population spike amplitude in CA1 hippocampal neurons [29]. Conversely, there is evidence that 5 -HT7 receptor agonists decrease glutamate-induced intracellular calcium release [11] and the amplitude of glutamate EPSPs [12]. Based on the findings reported here and our previous report describing the ability of long-term 5-HT7 receptor agonist treatment to upregulate PDGF $\beta$ receptors $[16,18]$, we propose that the activation of 5-HT7 receptors may regulate NMDA receptor activity via two temporally distinct pathways (Figure 6): Acute $(5 \mathrm{~min})$ activation of 5 -HT7 receptors increases NMDA-evoked currents whereas long-term (2-24 h) activation of 5-HT7 receptors upregulates PDGF $\beta$ receptors, a receptor tyrosine kinase that inhibits NMDA receptor activity $[17,18,30]$.

5-HT7 receptors are involved in aspects of learning and memory associated with hippocampal function [31]. For example, 5-HT7 receptor knock-out mice display impaired contextual fear-conditioning [13] and display a reduced ability to recognize new environments [32]. These and other studies have promoted interest in 5-HT7 receptors as a potential drug target in Alzheimer's disease and are further supported by a study demonstrating an increase in memory formation by a 5-HT7 receptor agonist, AS 19 [33]. NMDA receptors are crucial components of learning and memory pathways in the hippocampus. Thus, the positive linkage between 5 -HT7 receptors and NMDA receptor activity may explain how 5 -HT7 receptors promote learning and memory as well as their involvement in LTP.

Since all three 5-HT7 receptor splice variants identified in rats are positively coupled with adenylate cyclase and display some level of constitutive activity [8], it is not surprising that the activation of 5-HT7 receptors in hippocampal slices increases the phosphorylation of the NR1 subunit at serine 897. On the NR2B subunit, tyrosine 1472 is required/involved in CaMKII binding and activation [34] and this phosphorylation site is linked to spinal pain transmission [35]. Interestingly, 5-HT7 receptors agonists promote pain after formalin injection in 


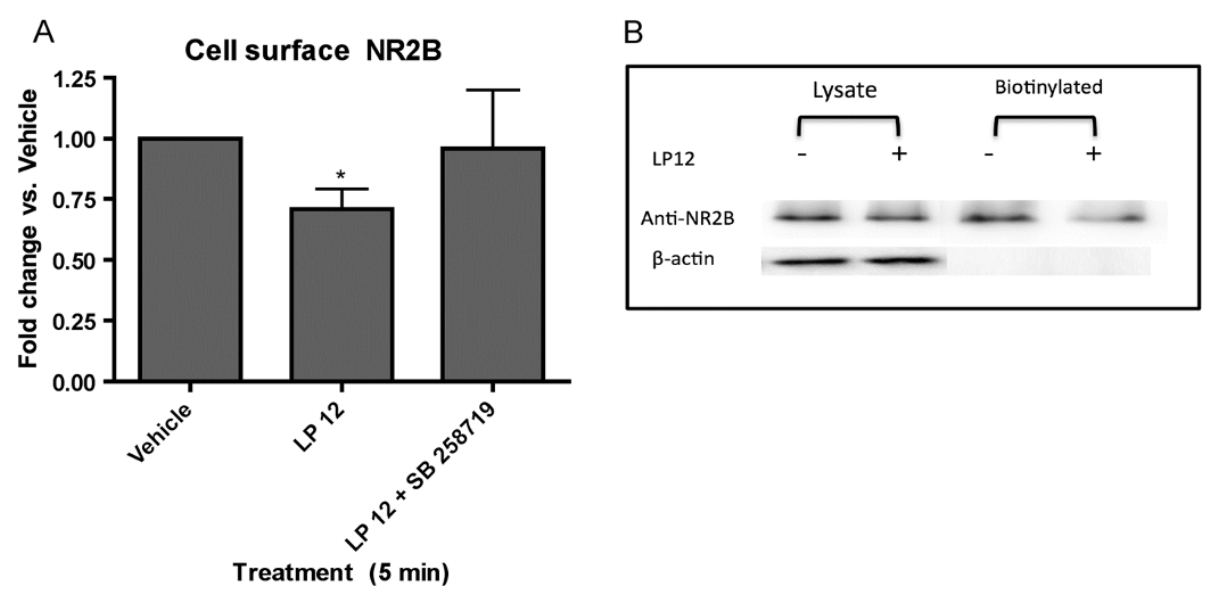

Figure 5 LP 12 application results in the selective reduction of the surface expression of NR2B. A) CA1 hippocampal slices were treated with vehicle, 300 nM LP 12, or LP 12+ 1 HM SB 258719 for 5 min. The slices were biotinylated and lysates were incubated overnight with streptavidin beads. Data represent the average and standard error of 6 independent experiments. ${ }^{*} p<0.05$ LP 12 vs. vehicle ANOVA analysis with Dunnett's posttest. B) Total lysates or biotinylated samples were blotted using antibodies against NR2B or $\beta$-actin.

animal models [36] however others have found antinociceptive effects of 5-HT7 receptors [37,38]. These differences may be due to distinct central and peripheral pain pathways that both contain 5-HT7 receptors.

\section{Conclusions}

In summary, we have now identified two pathways downstream of the 5-HT7 receptor that ultimately regulate NMDA receptor activity/signaling (Figure 6). We have demonstrated that the upregulation of PDGF $\beta$ receptors by long-term treatment with 5 -HT7 receptor agonists is sufficient to protect hippocampal neurons against NMDA excitotoxicity $[16,18]$ whereas acute activation of 5-HT7 receptors increased NMDA-evoked currents. These findings may help to explain why previous reports identified
5-HT7 receptors as both positive and negative regulators of NMDA receptor signaling.

\section{Materials and methods}

Reagents and antibodies

5-CT, LP 12 (4-(2-Diphenyl)-N-(1,2,3,4-tetrahydronaphthalen-1-yl)-1- piperazinehexanamide hydrochloride), and H89 were purchased from Sigma (St. Louis, MO, USA). The 5-HT7 receptor antagonists SB 258719 ((R)3,N-Dimethyl-N-[1-methyl-3-(4-methylpiperidin-1-yl) propyl]benzene sulfonamide) and SB 269970 (R-3-(2-(2(4-methylpiperidin-1-yl)ethyl)-pyrrolidine-1-sulfonyl)-phenol as well as Go 6983 were purchased from Tocris (Ellisville, MO, USA). Antibodies purchased from Millipore (Bellerica, MA) include anti-NR1, anti-phospho-896-NR1,

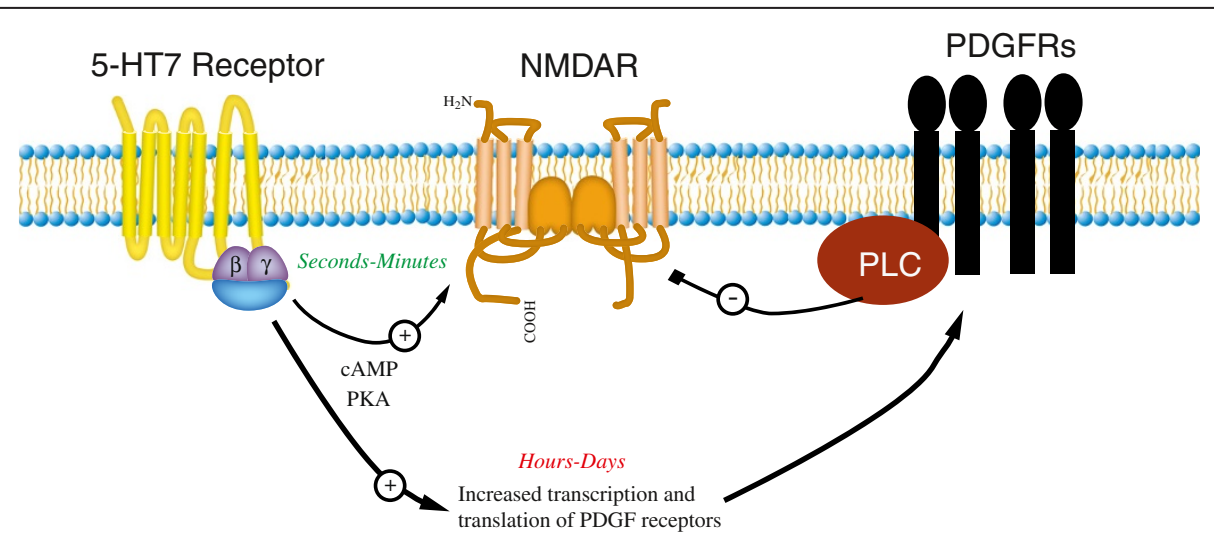

Figure 6 Proposed model for NMDA receptor regulation by short- and long-term activation of 5-HT7 receptors. Prolonged (2 to $24 \mathrm{~h})$ activation of 5-HT7 receptors up regulates PDGF receptor activation and expression in hippocampal neurons, cortical neurons, and SH-SY5Y cells. The upregulation of PDGF $\beta$ receptors is sufficient to inhibit NMDA-induced neuronal cell death in primary cultures. In addition, NMDA receptor subunit expression is reduced. In contrast, acute (5 $\mathrm{min}$ ) activation of 5-HT7 receptors increases NMDA-evoked currents and differentially regulates NMDA receptor subunit phosphorylation and cell surface expression. Figure modified from [18]. 
anti-phospho-897-NR1, anti-NR2A, anti-phospho-panNR2A, anti-NR2B, anti-phospho-1252-NR2B, anti-phospho1336-NR2B, and anti-phospho-1472-NR2B.

\section{Cell isolation and whole-cell recording}

CA1 neurons were isolated from hippocampal slices of postnatal day 14-21 Wistar rats as previously described [39]. The extracellular solution was composed of $140 \mathrm{mM}$ $\mathrm{NaCl}, 1.3 \mathrm{mM} \mathrm{CaCl}_{2}, 25 \mathrm{mM} \mathrm{N}$-2-hydroxyethylpiperazine$\mathrm{N}$ '-ethanesulfonic acid (HEPES), $33 \mathrm{mM}$ glucose, $5.4 \mathrm{mM}$ $\mathrm{KCl}$, and $0.5 \mu \mathrm{M}$ tetrodotoxin, and $0.5 \mu \mathrm{M}$ glycine, with $\mathrm{pH}$ of 7.3-7.4 and osmolarity ranging from 320-330 mOsm. Recordings were done at room temperature. The intracellular solution consisted of $11 \mathrm{mM}$ ethyleneglycol-bis- $(\alpha-$ amino-ethyl ether) N,N'-tetra-acetic acid (EGTA) as intracellular calcium chelating buffer, $10 \mathrm{mM}$ HEPES, $2 \mathrm{mM}$ $\mathrm{MgCl}_{2}, 2 \mathrm{mM}$ tetraethyl ammonium chloride (TEA-Cl) to block $\mathrm{K}+$ channel, $1 \mathrm{mM} \mathrm{CaCl}_{2}, 140 \mathrm{mM} \mathrm{CsF}$, and $4 \mathrm{mM}$ $\mathrm{K}_{2} \mathrm{ATP}$. NMDA currents were evoked by rapid application of NMDA solution delivered from a multi-barreled fast perfusion system for $2 \mathrm{~s}$ every minute.

\section{Western blot}

Hippocampal slices were prepared, treated with drugs for $5 \mathrm{~min}$, and homogenized chilled lysis buffer (20 mM Tris$\mathrm{HCl}$ at $\mathrm{pH}$ 7.5, $150 \mathrm{mM} \mathrm{NaCl}, 1 \mathrm{mM}$ EDTA, 1 mM EGTA, $30 \mathrm{mM}$ sodium pyrophosphate, $1 \mathrm{mM} \beta$-glycerophosphate, $1 \mathrm{mM}$ sodium orthovanadate, $0.5 \%$ SDS, and $1 \%$ tritonX-100; supplemented with Halt Protease and Phosphatase Inhibitor (Thermo, Fisher, Markham, Ontario)) prior to use. Lysates were centrifuged at $14,000 \times \mathrm{g}$ for $20 \mathrm{~min}$ at $4^{\circ} \mathrm{C}$ and the supernatant was collected. The supernatant was subjected to SDS-PAGE and proteins were transferred to nitrocellulose membranes, blocked with 5\% non-fat dry milk in Tris-buffered saline and $0.1 \%$ Tween for $1 \mathrm{~h}$ at room temperature or overnight at $4^{\circ} \mathrm{C}$, and incubated in primary antibodies for $1 \mathrm{~h}$ at room temperature or overnight at $4^{\circ} \mathrm{C}$. Membranes were washed three times in Tris-buffered saline with 0.1\% Tween-20, incubated with HRP-conjugated secondary antibodies for $1 \mathrm{~h}$ at room temperature, washed again, and bound antibodies were visualized by the enhanced chemiluminescence using the chemiluminescent substrate (Millipore, Etobicoke, Ontario). Images of Western blots were taken on the Kodak 4000 MM Pro Imaging Station, and densitometric analyses were performed using the Kodak Molecular Imaging software. Membranes were then stripped and reprobed with other antibodies.

\section{Surface biotinylation assay}

Hippocampal slices were incubated for 5 min with 5-HT7 receptor agonists and antagonists. Slices were washed in ice-cold ECF and incubated with $0.5 \mathrm{mg} / \mathrm{ml}$ Sulfo-NHS-
LC-biotin (Pierce) for $30 \mathrm{~min}$. The biotin reaction was quenched by washing with $10 \mathrm{mM}$ glycine. Slices were washed twice more and homogenized in lysis buffer. Lysate protein concentrations were normalized and lysates were incubated with streptavidin beads overnight at $4^{\circ} \mathrm{C}$ (Sigma). Beads were washed three times in lysis buffer and boiled in loading buffer for $5 \mathrm{~min}$ before separation by SDS-PAGE.

\section{Statistical analysis}

Statistical analysis of the data was performed using the Prism $^{\circledast}$ GraphPad program. For electrophysiology, graphs and sample tracings were made using the Origin ${ }^{\circledR}$ program. Significance level was set at $\alpha=0.05$. Data was analyzed by one-way ANOVA or Student's t-test where appropriate.

\section{Animals}

All animal experiments were performed in agreement with the guidelines of the policies on the Use of Animals at the University of Waterloo (protocol \#09-17) and the University of Western Ontario.

\section{Abbreviations}

5-HT: 5-hydroxytryptamine; 5-CT: 5-carboxamidotryptamine; DRN: Ddorsal Raphe nucleus; EPSP: Excitatory post-synaptic potentials; LTP: Long-term potentiation; NMDA: N-methyl-D-aspartate; PDGF: Platelet-derived growth factor; SCN: Ssuprachiasmatic nucleus.

\section{Competing interests}

The authors declare that they have no competing interests.

\section{Authors' contributions}

MSV carried out the Western blot and biotinylation experiments and KY performed the electrophysiology experiments under the supervision of JFM and MFJ. JL and JSK contributed to the biochemical experimentation and participated in the drafting of the manuscript. JJH co-supervised MSV and JSK and participated in the drafting the manuscript. MAB conceived of the study, participated in its design and coordination, participated in the drafting of the manuscript, and supervised JL, MSV, and JSK. All authors read and approved the final manuscript.

\section{Acknowledgments}

Special thanks to Nancy Gibson and Dawn McCutcheon for their animal care and use of their facility while ours was under construction. This research was funded through generous start-up funding from the University of Waterloo, Faculty of Science and by the National Science and Engineering Research Council of Canada. The contributions of KY and JFM to this manuscript were supported by the Canadian Institutes of Health Research.

\section{Author details}

'Department of Biology, 200 University Ave. W, Waterloo, ON N2L 3G1, Canada. ${ }^{2}$ Department of Physiology, University of Toronto, Medical Sciences Bldg., 1 King's College Circle, Toronto, ON M5S 1A8, Canada. ${ }^{3}$ Robarts Research Institute, Western University, 100 Perth Drive, London, ON N6A 5K8, Canada. ${ }^{4}$ School of Pharmacy, 200 University Ave. W, Waterloo, ON N2L 3G1, Canada.

Received: 17 January 2013 Accepted: 6 May 2013 Published: 14 May 2013

\section{References}

1. Paoletti P, Neyton J: NMDA receptor subunits: function and pharmacology. Curr Opin Pharmacol 2007, 7:39-47. 
2. Al-Hallaq RA, Conrads TP, Veenstra TD, Wenthold RJ: NMDA di-heteromeric receptor populations and associated proteins in rat hippocampus. J Neurosci 2007, 27:8334-8343.

3. Rauner C, Kohr G: Triheteromeric NR1/NR2A/NR2B receptors constitute the major $\mathrm{N}$-methyl-D-aspartate receptor population in adult hippocampal synapses. J Biol Chem 2011, 286:7558-7566.

4. Yuen EY, Jiang Q, Chen P, Gu Z, Feng J, Yan Z: Serotonin 5-HT1A receptors regulate NMDA receptor channels through a microtubule-dependent mechanism. J Neurosci 2005, 25:5488-5501.

5. Liang $X$, Arvanov VL, Wang RY: Inhibition of NMDA-receptor mediated response in the rat medial prefrontal cortical pyramidal cells by the 5-HT3 receptor agonist SR 57227A and 5-HT: intracellular studies. Synapse 1998, 29:257-268.

6. Blank T, Zwart R, Nijholt I, Spiess J: Serotonin 5-HT2 receptor activation potentiates $\mathrm{N}$-methyl-D-aspartate receptor-mediated ion currents by a protein kinase C-dependent mechanism. J Neurosci Res 1996, 45:153-160

7. Arvanov $V L$, Liang $X$, Magro $P$, Roberts $R$, Wang RY: A pre- and postsynaptic modulatory action of 5- $\mathrm{HT}$ and the $5-\mathrm{HT} 2 \mathrm{~A}, 2 \mathrm{C}$ receptor agonist $\mathrm{DOB}$ on NMDA-evoked responses in the rat medial prefrontal cortex. Eur J Neurosci 1999, 11:2917-2934.

8. Leopoldo M, Lacivita E, Berardi F, Perrone R, Hedlund PB: Serotonin 5-HT7 receptor agents: Structure-activity relationships and potential therapeutic applications in central nervous system disorders. Pharmacol Ther 2011, 129:120-148.

9. Duncan MJ, Congleton MR: Neural mechanisms mediating circadian phase resetting by activation of $5-\mathrm{HT}(7)$ receptors in the dorsal raphe: roles of GABAergic and glutamatergic neurotransmission. Brain Res 2010 1366:110-119.

10. Harsing LG Jr, Prauda I, Barkoczy J, Matyus P, Juranyi Z: A 5-HT7 heteroreceptor-mediated inhibition of $[3 \mathrm{H}]$ serotonin release in raphe nuclei slices of the rat: evidence for a serotonergic-glutamatergic interaction. Neurochem Res 2004, 29:1487-1497.

11. Smith BN, Sollars PJ, Dudek FE, Pickard GE: Serotonergic modulation of retinal input to the mouse suprachiasmatic nucleus mediated by 5-HT1B and 5-HT7 receptors. J Biol Rhythms 2001, 16:25-38.

12. Quintero JE, MCMahon DG: Serotonin modulates glutamate responses in isolated suprachiasmatic nucleus neurons. J Neurophysiol 1999, 82:533-539.

13. Roberts AJ, Krucker T, Levy CL, Slanina KA, Sutcliffe JG, Hedlund PB: Mice lacking 5-HT receptors show specific impairments in contextual learning. Eur J Neurosci 2004, 19:1913-1922.

14. Crider JY, Williams GW, Drace CD, Katoli P, Senchyna M, Sharif NA: Pharmacological characterization of a serotonin receptor (5-HT7) stimulating CAMP production in human corneal epithelial cells. Invest Ophthalmol Vis Sci 2003, 44:4837-4844.

15. Kvachnina E, Liu G, Dityatev A, Renner U, Dumuis A, Richter DW, Dityateva G, Schachner M, Voyno-Yasenetskaya TA, Ponimaskin EG: 5-HT7 receptor is coupled to $\mathrm{G}$ alpha subunits of heterotrimeric $\mathrm{G} 12$-protein to regulate gene transcription and neuronal morphology. J Neurosci 2005, 25:7821-7830

16. Vasefi MS, Kruk JS, Liu H, Heikkila JJ, Beazely MA: Activation of 5-HT7 receptors increases neuronal platelet-derived growth factor beta receptor expression. Neurosci Lett 2012, 511:65-69.

17. Beazely MA, Lim A, Li H, Trepanier C, Chen X, Sidhu B, Macdonald JF: Platelet-derived growth factor selectively inhibits NR2B-containing $\mathrm{N}$-methyl-D-aspartate receptors in CA1 hippocampal neurons. J Biol Chem 2009, 284:8054-8063.

18. Vasefi MS, Kruk JS, Heikkila JJ, Beazely MA: 5-HT7 receptor neuroprotection against NMDA-induced excitotoxicity is PDGFß receptor-dependent. J Neurochem 2013, 125:26-36.

19. Eglen RM, Jasper JR, Chang DJ, Martin GR: The 5-HT7 receptor: orphan found. Trends Pharmacol Sci 1997, 18:104-107.

20. Hoyer D, Clarke DE, Fozard JR, Hartig PR, Martin GR, Mylecharane EJ, Saxena PR, Humphrey PP: International Union of Pharmacology classification of receptors for 5-hydroxytryptamine (Serotonin). Pharmacol Rev 1994, 46:157-203.

21. Mahe C, Bernhard M, Bobirnac I, Keser C, Loetscher E, Feuerbach D, Dev KK Schoeffter $P$ : Functional expression of the serotonin 5-HT7 receptor in human glioblastoma cell lines. Br J Pharmacol 2004, 143:404-410.

22. Romero G, Pujol M, Pauwels PJ: Reanalysis of constitutively active rat and human 5-HT7(a) receptors in HEK-293F cells demonstrates lack of silent properties for reported neutral antagonists. Naunyn Schmiedebergs Arch Pharmacol 2006, 374:31-39.

23. Andressen KW, Norum JH, Levy FO, Krobert KA: Activation of adenylyl cyclase by endogenous $\mathrm{G}(\mathrm{s})$-coupled receptors in human embryonic kidney 293 cells is attenuated by $5-\mathrm{HT}(7)$ receptor expression. $\mathrm{Mol}$ Pharmacol 2006, 69:207-215.

24. Krobert KA, Bach T, Syversveen T, Kvingedal AM, Levy FO: The cloned human 5-HT7 receptor splice variants: a comparative characterization of their pharmacology, function and distribution. Naunyn Schmiedebergs Arch Pharmacol 2001, 363:620-632.

25. Thomas EA, Cravatt BF, Sutcliffe JG: The endogenous lipid oleamide activates serotonin 5-HT7 neurons in mouse thalamus and hypothalamus. J Neurochem 1999, 72:2370-2378.

26. Leopoldo M, Lacivita E, Contino M, Colabufo NA, Berardi F, Perrone R: Structure-activity relationship study on N-(1,2,3,4-tetrahydronaphthalen1-yl)-4-aryl-1-piperazinehexanamides, a class of 5-HT7 receptor agents. 2. J Med Chem 2007, 50:4214-4221.

27. Mahe C, Loetscher E, Feuerbach D, Muller W, Seiler MP, Schoeffter P: Differential inverse agonist efficacies of SB-258719, SB-258741 and SB-269970 at human recombinant serotonin 5-HT7 receptors. Eur J Pharmacol 2004, 495:97-102.

28. Bacon WL, Beck SG: 5-Hydroxytryptamine(7) receptor activation decreases slow afterhyperpolarization amplitude in CA3 hippocampal pyramidal cells. J Pharmacol Exp Ther 2000, 294:672-679.

29. Tokarski K, Zahorodna A, Bobula B, Hess G: 5-HT7 receptors increase the excitability of rat hippocampal CA1 pyramidal neurons. Brain Res 2003, 993:230-234.

30. Valenzuela CF, Xiong Z, MacDonald JF, Weiner JL, Frazier CJ, Dunwiddie TV, Kazlauskas A, Whiting PJ, Harris RA: Platelet-derived growth factor induces a long-term inhibition of N-methyl-D-aspartate receptor function. J Biol Chem 1996, 271:16151-16159.

31. Meneses A: Effects of the 5-HT7 receptor antagonists SB-269970 and DR 4004 in autoshaping Pavlovian/instrumental learning task. Behav Brain Res 2004, 155:275-282.

32. Sarkisyan G, Hedlund PB: The $5-H T 7$ receptor is involved in allocentric spatial memory information processing. Behav Brain Res 2009, 202:26-31.

33. Perez-Garcia GS, Meneses A: Effects of the potential 5-HT7 receptor agonist AS 19 in an autoshaping learning task. Behav Brain Res 2005, 163:136-140.

34. Nakazawa T, Komai S, Watabe AM, Kiyama Y, Fukaya M, Arima-Yoshida F, Horai R, Sudo K, Ebine K, Delawary M, et al: NR2B tyrosine phosphorylation modulates fear learning as well as amygdaloid synaptic plasticity. EMBO J 2006, 25:2867-2877.

35. Katano T, Nakazawa T, Nakatsuka T, Watanabe M, Yamamoto T, Ito S: Involvement of spinal phosphorylation cascade of Tyr1472-NR2B, Thr286-CaMKII, and Ser831-GluR1 in neuropathic pain. Neuropharmacology 2011, 60:609-616.

36. Rocha-Gonzalez HI, Meneses A, Carlton SM, Granados-Soto V: Pronociceptive role of peripheral and spinal 5-HT7 receptors in the formalin test. Pain 2005, 117:182-192.

37. Dogrul A, Seyrek M: Systemic morphine produce antinociception mediated by spinal 5-HT7, but not 5-HT1A and 5-HT2 receptors in the spinal cord. Br J Pharmacol 2006, 149:498-505.

38. Brenchat A, Romero L, Garcia M, Pujol M, Burgueno J, Torrens A, Hamon M, Baeyens JM, Buschmann H, Zamanillo D, Vela JM: 5-HT7 receptor activation inhibits mechanical hypersensitivity secondary to capsaicin sensitization in mice. Pain 2009, 141:239-247.

39. Wang LY, MacDonald JF: Modulation by magnesium of the affinity of NMDA receptors for glycine in murine hippocampal neurones. J Physiol 1995, 486(Pt 1):83-95.

doi:10.1186/1756-6606-6-24

Cite this article as: Vasefi et al:: Acute 5 -HT7 receptor activation increases NMDA-evoked currents and differentially alters NMDA receptor subunit phosphorylation and trafficking in hippocampal neurons. Molecular Brain 2013 6:24. 